\title{
Alkali activated binders: Challenges and opportunities
}

\author{
P.O. Awoyera ${ }^{a, *}$, A. Adesina ${ }^{b}$, A. Sivakrishna ${ }^{c}$, R. Gobinath ${ }^{c}$, K. Rajesh Kumar ${ }^{c}$, A. Srinivas ${ }^{c}$ \\ ${ }^{a}$ Department of Civil Engineering, Covenant University, Ota, Nigeria \\ ${ }^{\mathrm{b}}$ Windsor University, Windsor, Canada \\ ${ }^{\mathrm{c}}$ Department of Civil Engineering, SR Engineering College, Warangal, Telangana, India
}

\section{A R T I C L E I N F O}

\section{Article history:}

Received 6 July 2019

Received in revised form 25 July 2019

Accepted 20 August 2019

Available online 7 September 2019

\section{Keywords:}

Alkali activated binders

Concrete

Ordinary Portland cement

Pozzolan

Sustainability

\begin{abstract}
A B S T R A C T
Alkali activated binders $(\mathrm{AAB})$ are gaining huge research attention in recent years, due to their potential to totally be used in a zero-cement composite. Ordinary Portland cement (OPC) is characterized by high energy usage and carbon emission from its production process, which thus shows the need for $A A B$ development. $A A B$ are a sustainable replacement for OPC, as they can be produced from waste materials generated by various industrial processes. This paper explored the properties of different types of waste used as a solitary and binary combination for $A A B$, alongside their effects on the resulting composites. A general summary of the opportunities of AABs are also discussed. It was concluded that, with more research and developments dedicated to the field of $\mathrm{AAB}, \mathrm{AAB}$ can be practical replacement of OPC for large-scale applications in the near future.

(c) 2019 Elsevier Ltd. All rights reserved.

Selection and peer-review under responsibility of the scientific committee of the First International Conference on Recent Advances in Materials and Manufacturing 2019.
\end{abstract}

\section{Introduction}

The base building material used for our infrastructure is concrete, and it has been used since the ancient times, and will still be in use for centuries to come. Over the decades, the composition and properties of concrete have evolved, and more evolution is anticipated in coming years. The recent awareness about the sustainability of our environment has called for an action in all industries to make our environment safe, and the concrete industry is not excluded $[1,2]$. The concrete industry has a huge role to play in the world's sustainability because ordinary Portland cement (OPC) which is the main binder used in concrete is one of the major contributors of the world's anthropogenic carbon emission. For every ton of OPC produced, an equivalent amount of carbon dioxide is emitted into the environment $[3,4]$. Therefore, in order to keep our environment safe while meeting the rising demand for concrete/cement, it is paramount to find alternative options that can replace OPC in concrete. One of the most promising binder to replace OPC is the alkali-activated binder. Duxson et al. [5] have reported a reduction of carbon dioxide emission up to $80 \%$ with the use of $A A B$ compared to that of OPC. AAB are produced by activating an aluminosilicate precursor with an alkali medium. The

\footnotetext{
* Corresponding author.

E-mail address: paul.awoyera@covenantuniversity.edu.ng (P.O. Awoyera).
}

prospect of this material is high because it can totally replace OPC in concrete, and the aluminosilicate precursors used are waste materials obtained from different industrial processes. Most studies in the last century have focused on improving the properties of OPC concrete, however, with increasing sustainability awareness, this last decade has seen a shift in more research now dedicated to alkali activated materials [6]. The sustainability advantage coupled with its potential enhanced properties has contributed significantly to this paradigm. However, there's still a huge limitation with the use of $A A B$ in terms of its fresh and hardened properties which limits its commercial and large-scale production. In order for $A A B$ to be universally accepted and compete with the OPC usage, these challenges have to be overcome. Compared to the yet to be published article by the author [7] and other overviews in the field of $A A B$, this article focused extensively on the aluminosilicate precursors (i.e. fly ash, slag, metakaolin, etc.) used to make the binders instead of the general problems of AABs. The most common types of activator used for $A A B$ are sodium silicate and/or sodium hydroxide. And these activators possess a huge threat on some of the properties of concrete. In addition, these types of activators are not user or eco-friendly. However, to create a uniform comparison, the $A A B$ explored herein were activated with sodium silicate and/or sodium hydroxide except where stated otherwise. Though several contradictions still exist in the research field about the difference between geopolymers and alkali 
activated materials. The author herein encompasses all types of binders obtained by alkali activation as alkali activated binder. It is hoped that this article will contribute to the knowledge of various scientist working on improving AABs, and that possible solutions to the challenges will be developed in the nearest future.

\section{Alkali activated binders}

The properties of $A A B$ are strongly influenced by the type of aluminosilicate employed. $A A B$ are classified herein as either solitary or binary depending on whether the aluminosilicate precursor is used individually or combined with other types. The resulting properties of some of $A A B$ made with the various type of aluminosilicate and their major limitations are briefly discussed as follows:

\subsection{Solitary $A A B$}

\subsubsection{Flyash}

Despite the high amount of fly ash generated from power stations all over the world, only a minute amount is being utilized while the rest are dumped in landfill or left in open spaces where they contaminate the environment. Type F fly ash is the most common type of fly ash used because of its low calcium content which eliminates the disadvantage of rapid setting associated with high calcium fly ash (i.e. type $\mathrm{C}$ ) [8]. Also, type $\mathrm{F}$ is more readily available compared to type $C$ [5]. However, one of the major issues associated with the use of alkali activated fly ash as a binder is its high curing temperature requirement. This high temperature used for curing increases the overall embodied energy and carbon of the resulting binder thereby eliminating is eco-advantage. The high temperature is required to improve the strength of the $A A B$ by increasing the rate of dissolution of the ions which further forms a gel and harden with time. Higher strength has been reported for this type of $A A B$ when cured at a temperature of about $85^{\circ} \mathrm{C}$ [9]. In a study by Xie and Xi [10], a curing temperature line of $55^{\circ} \mathrm{C}$ was recommended as the strength achieved below this temperature is very low. However, even curing at $55^{\circ} \mathrm{C}$ consume a large amount of energy compared to curing at ambient conditions, and this further leads to a consequential emission of carbon dioxide into the environment. Bakharev [11] also reported that AABs made with fly ash have poor resistance to acid attack irrespective of the type of activator he used. This poor resistance was ascribed to depolymerization and dealumination [11].

\subsubsection{Slag}

Slag is a waste product from the metal production industry, and it contains a high percentage of calcium. Sodium silicate is the most used activator for slag, and this is as a result of its higher mechanical properties compared to other activators. However, the use of sodium silicate is associated with the various detrimental effect on both the fresh and hardened properties of the alkali activated slag. The major problems on the fresh and hardened properties are short set times and high shrinkage respectively $[12,13]$. The short set time creates a huge handling challenge as this prevents it from most applications. Shi et al. [14] have reported the shrinkage of $A A B$ made from slag as a solitary binder to be higher than that of OPC. Shrinkage of about four times that of OPC was also reported by Palacios and Puertas [15] when slag was activated with sodium silicate. In terms of durability; earlier study by Gifford and Gillot [13] in Canada suggested that alkali activated slag are more prone to alkali carbonate reaction, though the possibility of alkali silica reaction to occur is lower. In another early stud by Byfros et al. [16], AAB with slag as aluminosilicate precursor undergoes rapid carbonation compared to that of OPC, though the test methods employed has been challenged for its inaccuracy for $\mathrm{AAB}$. The use of slag above a certain optimum limit has also been reported to result in higher carbonation due to selfdesiccation and formation of microcracks in the matrix $[17,18]$.

\subsubsection{Metakaolin}

Metakaolin is obtained by heating kaolin at high temperatures of about $750{ }^{\circ} \mathrm{C}$ for a certain duration. The product formed during the alkali activation of metakaolin are typically affected by the properties and type of the parent kaolin and activator used $[19,20]$. Improved strength of alkali activated metakaolin is observed when sodium silicate and sodium hydroxide is used to activate it compared to when only sodium hydroxide was used [19]. However, metakaolin based $A A B$ are also attributed with bad workability which poses a huge challenge to its mixing and placing.

\subsubsection{Red mud}

Red mud is a high alkali waste generated from the alumina refining and can be referred to as bauxite due to its parent ore [21]. Some attempts have been made to use red mud as a solitary $A A B$, however, in order to achieve enhanced strength, heat treatment is required [22]. This heat treatment increases the energy usage and carbon dioxide emission into the atmosphere, which partly eliminates the sustainability advantage of AAB. Red mud has strong alkaline property, which suggest that it can be utilized as an activator for other AABs. Also, with the afo mentioned study showing that, red mud has lower grain size $(2.75 \mu \mathrm{m})$ than cement particles (4-6 $\mu \mathrm{m})$, it thus suggests that it can actively function as a filler, improving packing effect on binder matrix and improving overall strength development.

\subsubsection{Palm oil fuel ash}

Palm oil fuel ash (POFA) is a by-product of the agricultural industry. High deterioration of alkali activated palm oil fuel ash used as solitary $A A B$ has been reported when it was exposed to a sulphate environment [23]. This deterioration was also accompanied by a significant reduction in compressive strength and mass. However, POFA is rich in calcium, which is an indication that it can be used to develop composite with higher strength properties. Moreover, there are tendencies of higher strength $A A B$ composite to be developed, if POFA is dosed with other active AABs, such fly ash, metakaolin and slag.

\subsection{Binary $A A B S$}

\subsubsection{Slag and metakaolin}

Use of metakaolin alongside slag as $A A B$ has been found to result in lower strength compared to the solitary use of slag [24]. The reduction trend in the compressive strength also continued with an increase in the metakaolin content. Also, the binary combination of slag and metakaolin exhibited higher carbonation which increases with increase in the metakaolin content. The formation of both aluminosilicate gel and C-S-H phases has been reported when slag and metakaolin are alkali activated and used as a binary binder [25]. This observation of the coexistence of different phases was also confirmed in an extensively studied carried out by Buchwald et al. [26]. And the presence of these phases has been reported to result in enhanced strength of the resulting binder [26]. In addition, the use of metakaolin with slag results in lower heat generation and extended setting times of the binary $\mathrm{AAB}[24]$.

\subsubsection{Slag and silica fume}

Silica fume is a waste product from the production of ferrosilicon metals. Silica fume can be used to enhance the strength of the 
resulting $A A B$ when used in combination with slag up to $15 \%$ replacement level after which there is a decrease in strength of the $A A B$ [27]. However, there is a significant lower workability associated with $A A B$ made with a slag and silica fume as aluminosilicate precursors [28]. This detrimental effect will prevent the ease of mixing and placing the concrete for different applications. In addition, despite the enhancement of compressive strength to a certain level, a decrease in flexural strength was reported starting from $10 \%$ inclusion of silica fume [27]. Also, in terms of fire resistance, the study [27] also concluded that the use of a solitary blend of slag is more fire resistance compared to the binary blend of silica fume and slag. The lower fire resistance of slag-silica fume blend has been attributed to its volume instability which increases with the increase in the quantity of silica fume [27]. A similar observation was also made for resistance against thermal shock.

\subsubsection{Fly ash and slag}

This binary combination of fly ash and slag is the most studied in the open literature. Depending on the proportion of fly ash and slag used as binary, fly ash can be used to extend the setting time and improve the workability of the mixture [29], and slag to enhance the setting and early age development. However, the strength of this type of binary $A A B$ is found to be lower to that of using only slag as solitary AAB. CSH gel is the main product of the alkali activation of the binary combination of fly ash and slag as a binder [15]. Other products formed from the alkali activation are calcite, hydrotalcite and pirssonite. The binary combination of slag with fly ash also improves the reactivity of the fly ash [30]. However, increasing the content of fly ash in this binary binder has been reported to increase the porosity of the resulting matrix [31]. Severe deterioration of fly ash -slag combination as $A A B$ was observed when they are exposed to a sulphate solution [30], and this deterioration has been attributed to the formation of gypsum and decomposition of the C-S-H phase.

\subsubsection{Red mud and slag}

Ye et al. [32] were able to produce a binary blend AAB using red mud and slag, and activator employed was sodium silicate. However, similar to its solitary use, calcination at temperatures between $200^{\circ} \mathrm{C}$ and $1000^{\circ} \mathrm{C}$ for $3 \mathrm{~h}$ of the red mud was required, before further heat treatments. Compressive strength as high as 49.2 MPa was achieved and this can be duly attributed to the type and concentration of activator used (i.e. sodium silicate).

\subsubsection{Red mud and rice husk}

In an extensive study done by He et al. [21], they were able to activate the binary combination of red mud and rice husk with sodium hydroxide to produce AAB. Rice husk ash (RHA) is an agricultural waste obtained from the combustion of rice husk. Though compressive strength as high as $21 \mathrm{MPa}$ was achieved, extended curing time is required to achieve this higher strength. Also, despite the high mechanical properties, the ductility of the $A A B$ reduced with the curing time. The curing requirement and possible diminishing of properties possess a huge challenge on the large-scale application of this binary blend of $A A B$ [21]. In addition, similar to when red mud was used as a solitary $A A B$, thermal treatment is required to achieve higher strength which leads to an overall increase in the embodied energy and carbon of the AAB.

\subsubsection{Red mud and metakaolin}

Compressive strength up to $20 \mathrm{MPa}$ alongside high resistance to fire was achieved by alkali activation of red mud and metakaolin [32]. Despite the high compressive strength achieved, the flexural strength of the $A A B$ was very low. In addition, $A A B$ produced with red mud and metakaolin showed bad resistance to freeze and thaw
Table 1

Properties of selected AABs and binary AAB blends.

\begin{tabular}{lll}
\hline AAB & Effect in composite & Source \\
\hline Fly ash & Mostly gives high mechanical strength & {$[33]$} \\
Metakaolin & $\begin{array}{l}\text { Final product are made of a polymeric model } \\
\text { and high mechanical strength }\end{array}$ & {$[34]$} \\
Slag & $\begin{array}{l}\text { Higher mechanical strength of mortar, only } \\
\text { when activated with } \mathrm{Na}_{2} \mathrm{SiO}_{3} \cdot \mathrm{nH} 2 \mathrm{O}+\mathrm{NaOH}\end{array}$ & {$[35]$} \\
Red mud & $\begin{array}{l}\text { Higher composite strength } \\
\text { slow setting and low strength development of } \\
\text { POFA }\end{array}$ & {$[37]$} \\
Slag - red mud & $\begin{array}{l}\text { high early and ultimate strength and good } \\
\text { hesistance against chemical attacks } \\
\text { Fly ash - red mud }\end{array}$ & {$[38,39]$} \\
& $\begin{array}{l}\text { developed materials could produce controlled } \\
\text { low strength materials. }\end{array}$ & {$[40]$} \\
\hline
\end{tabular}

cycles which indicates it cannot be used for certain applications [32]. These detrimental properties of the AAB have been attributed to the weakly connected layers which are possibly caused as a result of low aluminate content in the matrix [32].

\section{Alkali activated binders' opportunities}

Despite the various challenges plaguing AABs, several opportunities still exist which can be improved on with time and, and more research and development. The major opportunities that can be achieved through the use of AABs in constructions are briefly discussed as follows;

1) Sustainable construction: The use of $A A B$ creates an avenue to reduce significantly the carbon emissions and energy usage from the production of OPC.

2) Waste management: Most of the aluminosilicate precursors used are waste materials, their use as a binder gives the waste a useful life and prevents possible contamination of the environment that might have resulted from their improper disposal.

3) Economical concrete: As mentioned earlier, the aluminosilicate materials are usually classified as waste before use as $A A B$, and they have zero value. With their use as a binder in concrete, they will be able to replace the most expensive component in conventional concrete which is OPC.

4) Meeting future building materials demand: Research has shown that the current natural deposit of raw materials used for OPC is been over consumed. Therefore, the use of AAB as the alternative binder will conserve these natural deposits of raw materials while meeting the high demand of binder for construction purposes

Finally, in order to highlight the impact of various AABs or their blends on a composite, the resulting mechanical characteristics of products have been identified in Table 1. Overall, it is clear that AABs enhanced strength development in the composites.

\section{Conclusions}

This study explores the challenges and opportunities in the use of alkali activated binders. The study concludes that:

Alkali activated binders have huge potential to replace the convention OPC, due to their eco-friendlier properties and enhanced properties. However, there are associated challenges in the use of $A A B$, which thus limit its usage. Based on the open literature explored; most challenges faced by AABs can be reduced or eliminated with the use of alternative activators that are more a more sustainable approach. Each type of aluminosilicate precursor is 
unique in its resulting properties when used as a solitary blend or in combination with other types of precursors. Therefore, it is essential to understand how each type behaves. In addition, with more research and developments dedicated to this area of study, AAB can be developed to a potential substitute for OPC in construction applications.

\section{References}

[1] P.O. Awoyera, A. Adesina, R. Gobinath, Role of recycling fine materials as filler for improving performance of concrete - a review, Aust. J. Civ. Eng. (2019) 111, https://doi.org/10.1080/14488353.2019.1626692.

[2] B. Arun Kumar, G. Sangeetha, A. Srinivas, P. Awoyera, R. Gobinath, V. Venkata Raman, Models for predictions of mechanical properties of low-density selfcompacting concrete prepared from mineral admixtures and pumice stone, Adv. Intell. Syst. Comput. (n.d.).

[3] V. Karthika, P.O. Awoyera, I.I. Akinwumi, R. Gobinath, R. Gunasekaran, N. Lokesh, Structural properties of lightweight self-compacting concrete made with pumice stone and mineral admixtures, Rev. Rom. Mater. Rom. J. Mater. 48 (2018).

[4] P. Murthi, P. Awoyera, P. Selvaraj, D. Dharsana, R. Gobinath, Using silica mineral waste as aggregate in a green high strength concrete: workability, strength, failure mode, and morphology assessment, Aust. J. Civ. Eng. (2018) 17, https://doi.org/10.1080/14488353.2018.1472539.

[5] P. Duxson, 3 - Geopolymer precursor design, in: J.L. Provis, J.S.J. van Deventer (Eds.), Geopolymers, Woodhead Publishing, 2009, pp. 37-49, 10.1533/ 9781845696382.1.37.

[6] P. Awoyera, A. Adesina, A critical review on application of alkali activated slag as a sustainable composite binder, Case Stud. Constr. Mater. (2019), https:// doi.org/10.1016/j.cscm.2019.e00268.

[7] A. Adesina, Alkali activated materials: review of current problems and possible solutions, in: SynerCrete'18 Int. Conf. Interdiscip. Approaches Cem. Mater. Struct. Concr., 24-26 October 2018, Funchal, Madeira Island, Portugal, n.d.

[8] P. Chindaprasirt, P. De Silva, K. Sagoe-Crentsil, S. Hanjitsuwan, Effect of SiO2 and $\mathrm{Al} 2 \mathrm{O} 3$ on the setting and hardening of high calcium fly ash-based geopolymer systems, J. Mater. Sci. 47 (2012) 4876-4883, https://doi.org/ 10.1007/s10853-012-6353-y.

[9] A. Palomo, T. Blanco-Valera, S. Alonso, L. Granizo, N, in: 11th Int. Congr. Chem. Cem., Durban, South Africa, 2003: p. 425.

[10] Z. Xie, Y. Xi, Hardening mechanisms of an alkaline-activated class F fly ash, Cem. Concr. Res. 31 (2001) 1245-1249, https://doi.org/10.1016/S0008-8846 (01)00571-3.

[11] T. Bakharev, Resistance of geopolymer materials to acid attack, Cem. Concr. Res. 35 (2005) 658-670, https://doi.org/10.1016/j.cemconres.2004.06.005.

[12] E. Douglas, A. Bilodeau, V. Malhotra, Properties and durability of alkali activated slag concrete, ACI Mater. J. 89 (1992) 509-516.

[13] P.M. Gifford, J.E. Gillott, Alkali-silica reaction (ASR) and alkali-carbonate reaction (ACR) in activated blast furnace slag cement (ABFSC) concrete, Cem. Concr. Res. 26 (1996) 21-26, https://doi.org/10.1016/0008-8846(95)00182-4.

[14] C. Shi, D. Roy, P. Krivenko, Alkali-Activated Cements and Concretes, Ist, CRC Press, London, 2003.

[15] F. Puertas, M. Palacios, T. Vázquez, Carbonation process of alkali-activated slag mortars, J. Mater. Sci. 41 (2006) 3071-3082, https://doi.org/10.1007/s10853005-1821-2.

[16] G.K. K. Byfors, V. Lehtonen, H. Pyy, and L. Romben, Durability of Concrete Made With Alkali-Activated Slag, Spec. Publ. 114 (n.d.). 10.14359/1827.

[17] P. Awoyera, A. Adesina, Durability properties of alkali activated slag composite: short overview, Silicon (2019).

[18] S.A. Bernal, R. San Nicolas, J.L. Provis, R. de Gutiérrez, J.S.J. van Deventer, Natural carbonation of aged alkali-activated slag concretes, Mater. Struct. 47 (2014) 693-707, https://doi.org/10.1617/s11527-013-0089-2.

[19] M.L. Granizo, M.T. Blanco-Varela, A. Palomo, Influence of the starting kaolin on alkali-activated materials based on metakaolin. Study of the reaction parameters by isothermal conduction calorimetry, J. Mater. Sci. 35 (2000) 6309-6315, https://doi.org/10.1023/A: 1026790924882.
[20] P.S. Singh, M. Trigg, I. Burgar, T. Bastow, Geopolymer formation processes at room temperature studied by 29Si and 27Al MAS-NMR, Mater. Sci. Eng. A 396 (2005) 392-402, https://doi.org/10.1016/j.msea.2005.02.002.

[21] J. He, Y. Jie, J. Zhang, Y. Yu, G. Zhang, Synthesis and characterization of red mud and rice husk ash-based geopolymer composites, Cem. Concr. Compos. 37 (2013) 108-118, https://doi.org/10.1016/j.cemconcomp.2012.11.010.

[22] M.O. Yusuf, Performance of slag blended alkaline activated palm oil fuel ash mortar in sulfate environments, Constr. Build. Mater. 98 (2015) 417-424, https://doi.org/10.1016/j.conbuildmat.2015.07.012.

[23] S.A. Bernal, J.L. Provis, V. Rose, R.M. de Gutierrez, Evolution of binder structure in sodium silicate-activated slag-metakaolin blends, Cem. Concr. Compos. 33 (2011) 46-54, https://doi.org/10.1016/j.cemconcomp.2010.09.004.

[24] C.K. Yip, G.C. Lukey, J.L. Provis, J.S.J. van Deventer, Effect of calcium silicate sources on geopolymerisation, Cem. Concr. Res. 38 (2008) 554-564.

[25] A.M. Rashad, M.H. Khalil, A preliminary study of alkali-activated slag blended with silica fume under the effect of thermal loads and thermal shock cycles, Constr. Build. Mater. 40 (2013) 522-532, https://doi.org/10.1016/ j.conbuildmat.2012.10.014.

[26] A. Buchwald, H. Hilbig, C. Kaps, Alkali-activated metakaolin-slag blendsperformance and structure in dependence of their composition, J. Mater. Sci. 42 (2007) 3024-3032, https://doi.org/10.1007/s10853-006-0525-6.

[27] F. Collins, J.G. Sanjayan, Effects of ultra-fine materials on workability and strength of concrete containing alkali-activated slag as the binder, Cem. Concr. Res. 29 (1999) 459-462, https://doi.org/10.1016/S0008-8846(98)00237-3.

[28] B. Talling, J. Brandstetr, Present State and Future of Alkali-Activated Slag Concretes, Spec. Publ. 114 (n.d.). 10.14359/1873.

[29] P. Duxson, J.L. Provis, Designing precursors for geopolymer cements, J. Am. Ceram. Soc. 91 (2008) 3864-3869, https://doi.org/10.1111/j.15512916.2008.02787.x.

[30] X. Gao, Q.L. Yu, H.J.H. Brouwers, Assessing the porosity and shrinkage of alkali activated slag-fly ash composites designed applying a packing model, Constr. Build. Mater. 119 (2016) 175-184, https://doi.org/10.1016/ j.conbuildmat.2016.05.026.

[31] N. Ye, J. Yang, X. Ke, J. Zhu, Y. Li, C. Xiang, H. Wang, L. Li, B. Xiao, Synthesis and characterization of geopolymer from bayer red mud with thermal pretreatment, J. Am. Ceram. Soc. 97 (2014) 1652-1660, https://doi.org/ 10.1111 /jace.12840.

[32] D.D. Dimas, I.P. Giannopoulou, D. Panias, Utilization of alumina red mud for synthesis of inorganic polymeric materials, Miner. Process. Extr. Metall. Rev. 30 (2009) 211-239, https://doi.org/10.1080/08827500802498199.

[33] A. Palomo, M.W. Grutzeck, M.T. Blanco, Alkali-activated fly ashes: a cement for the future, Cem. Concr. Res. 29 (1999) 1323-1329, https://doi.org/10.1016/ S0008-8846(98)00243-9.

[34] F. Pacheco-Torgal, J. Castro-Gomes, S. Jalali, Alkali-activated binders: a review: Part 1. Historical background, terminology, reaction mechanisms and hydration products, Constr. Build. Mater. 22 (2008) 1305-1314, https://doi. org/10.1016/j.conbuildmat.2007.10.015.

[35] A. Fernández-Jiménez, J.G. Palomo, F. Puertas, Alkali-activated slag mortars: mechanical strength behaviour, Cem. Concr. Res. 29 (1999) 1313-1321, https://doi.org/10.1016/S0008-8846(99)00154-4.

[36] Y. Li, X. Min, Y. Ke, D. Liu, C. Tang, Preparation of red mud-based geopolymer materials from MSWI fly ash and red mud by mechanical activation, Waste Manag. 83 (2019) 202-208, https://doi.org/10.1016/j.wasman.2018.11.019.

[37] M.A. Salih, N. Farzadnia, A.A.A. Ali, R. Demirboga, Development of high strength alkali activated binder using palm oil fuel ash and GGBS at ambient temperature, Constr. Build. Mater. 93 (2015) 289-300, https://doi.org/ 10.1016/j.conbuildmat.2015.05.119.

[38] Z. Pan, D. Li, J. Yu, N. Yang, Properties and microstructure of the hardened alkali-activated red mud-slag cementitious material, Cem. Concr. Res. 33 (2003) 1437-1441, https://doi.org/10.1016/S0008-8846(03)00093-0.

[39] S. Alam, S.K. Das, B.H. Rao, Strength and durability characteristic of alkali activated GGBS stabilized red mud as geo-material, Constr. Build. Mater. 211 (2019) 932-942, https://doi.org/10.1016/j.conbuildmat.2019.03.261.

[40] H. Choo, S. Lim, W. Lee, C. Lee, Compressive strength of one-part alkali activated fly ash using red mud as alkali supplier, Constr. Build. Mater. 125 (2016) 21-28, https://doi.org/10.1016/j.conbuildmat.2016.08.015. 